\title{
Troubleshooting of a left common carotid artery pseudoaneurysm as complication of central venous catheter placement
}

\author{
Juliane Dederer ${ }^{1} \cdot$ Peter Fries $^{2} \cdot$ Iman Madarati $^{1} \cdot$ Michael Böhm $^{1} \cdot$ Felix Mahfoud $^{1}$
}

Received: 18 April 2021 / Accepted: 4 May 2021

(c) The Author(s) 2021, corrected publication 2021

Sirs,

An 88-year-old female patient (height: $156 \mathrm{~cm}$, weight: $50 \mathrm{~kg}$ ) presented in the emergency department with chest pain, dyspnea, and edema of the lower extremities since 2 days. Troponin T, creatinine kinase, and creatinine kinase muscle-brain type were within normal ranges. In the electrocardiogram, there was no evidence of coronary ischemia. Clinical examination and laboratory testing indicated cardiac decompensation with an elevated NT-pro-BNP of $3371 \mathrm{pg} /$ $\mathrm{ml}$ (normal range up to the age of 75 years $<623 \mathrm{pg} / \mathrm{ml}$ ). Mitral valve repair was performed in 2006 because of acute, non-ischemic chordal rupture with a history of paroxysmal atrial fibrillation.

Oral treatment consisted of torasemide, metoprolol, apixaban, simvastatin, sitagliptin, and pantoprazole. The initial laboratory testing revealed severe hypokalemia (potassium $2.4 \mathrm{mmol} / 1$, normal range $3.5-5.1 \mathrm{mmol} / \mathrm{l}$ ). For highdose intravenous potassium substitution, it was planned to insert a central venous catheter (CVC) into the left internal jugular vein. The post-procedural chest X-ray showed an atypical projection of the CVC on the aortic arch and the left carotid artery indicating arterial malpositioning of the CVC (Fig. 1). The CVC was removed immediately, followed by manual compression of the puncture site for $15 \mathrm{~min}$ and compression with a sandbag over $1 \mathrm{~h}$. An alternative peripheral access in the right median cubital vein was established and the potassium level was subsequently normalized.

Juliane Dederer

Juliane.Dederer@uks.eu

1 Klinik für Kardiologie, Angiologie undInternistische Intensivmedizin, Universitätsklinikum des Saarlandes, Homburg, Germany

2 Klinik für Diagnostische und Interventionelle Radiologie, Universitätsklinikum des Saarlandes, Homburg, Germany
Duplex sonography the next day documented a pseudoaneurysm with an extension of $23 \times 11 \mathrm{~mm}$ in the proximal part of the common carotid artery with the characteristic to-and-fro sign by pulsed Doppler (Fig. 2a, b). The internal and external carotid arteries on both sides were free of stenosis or plaques. A contrast-enhanced computed tomography angiography excluded occult active bleeding (Fig. 2c).

Manual compression controlled by duplex sonography was initiated and treatment with apixaban was paused. Due to the higher temporal and spatial resolution, the linear LOGIQ L8-18i finger probe with a high transmission frequency of $15 \mathrm{MHz}$ was used, which also allowed targeted compression of the aneurysm neck due to the small probe size (Fig. 3a, b). The compression lasted for $20 \mathrm{~min}$, during which the common carotid artery was only slightly narrowed without alteration of the intraluminal blood flow. Afterwards, the pseudoaneurysm was completely thrombosed (Fig. 3c). The patient was continuously responsive and adequate, and no pathological neurological findings were present. Duplex sonography the following day, on day 2, and on day 9 showed complete thrombosis of the pseudoaneurysm.

The prevalence of arterial malpositioning associated with central venous access of the internal jugular vein ranges between 0.8 and $19 \%[1,2]$. The most common vascular complications associated with jugular vein punctures are injuries of the common carotid artery, but also accidental punctures of the brachiocephalic trunk, vertebral artery, thyrocervical trunk, and subclavian artery have been described $[3,4]$. In our patient, the so-called 'overlap phenomenon' existed, describing the anatomical situation of the internal jugular vein lying in front of the carotid artery [2]. In this situation, accidental arterial puncture is more likely, and may cause thromboembolic stroke, hemorrhage, arteriovenous fistula, dissection, and pseudoaneurysm. The latter occurs more frequently in patients with coagulation disorders and patients requiring oral anticoagulation therapy, respectively [3]. Pseudoaneurysms can quickly increase in volume and size and may compress adjacent structures such as veins and 


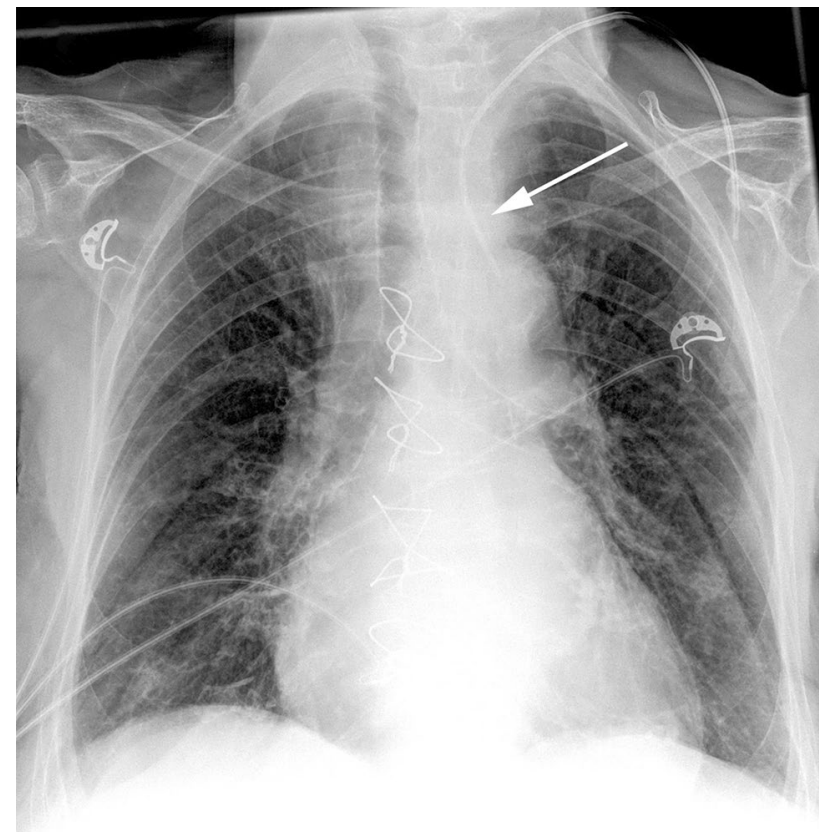

Fig. 1 Anterior-posterior chest X-ray demonstrates an atypical course of the inserted central venous catheter (arrow) with projection on the left common carotid artery and its tip on the aortic arch nerves with consecutive neurolysis and venous thrombosis, and can also rupture. Treatment of pseudoaneurysms include surgical and interventional therapies, such as resection, implantation of covered or flow diverting stents, or coiling as well as percutaneous thrombin injection and manual compression [5]. Both interventional and surgical repair may cause severe complications such as major and minor stroke, stent stenosis, and cardio-pulmonary complications and should, therefore, be considered as reserve options [6, 7]. Manual compression of the neck, however, may be challenging, because there is no hard abutment for firm compression of the aneurysm neck and sac. Furthermore, compression of the carotid arteries can be threatening, particularly in the presence of stenosis or plaques as it may cause cerebral hypoperfusion. In the present case, due to the proximal location of the pseudoaneurysm, a compression attempt with the LOGIQ L8-18i finger probe appeared promising and was finally successful, even though the patient was on effective oral anticoagulation (with an anti-Xa level in therapeutic range: $89.2 \mathrm{ng} / \mathrm{ml}$, normal range $34-162 \mathrm{ng} / \mathrm{ml}$ ).

Importantly, to avoid arterial malpositioning of a $\mathrm{CVC}$, one should get an idea of the location of the internal jugular vein and the carotid arteries and ideally perform

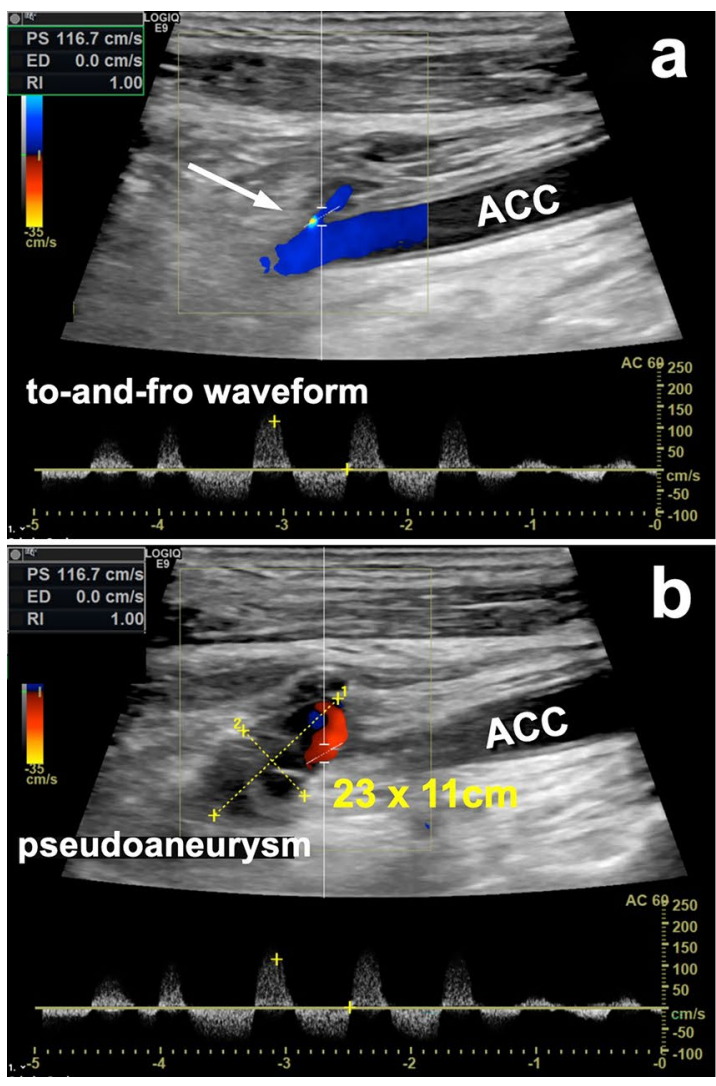

Fig. 2 a Depiction of the pseudoaneurysm-neck (arrow) outgoing of the common carotid artery (ACC) with to-and-fro waveform by pulse Doppler. b Color Doppler showing the pseudoaneurysm sac of $23 \times 11 \mathrm{~cm}$ with marginal thrombosis. c Cinematic rendering

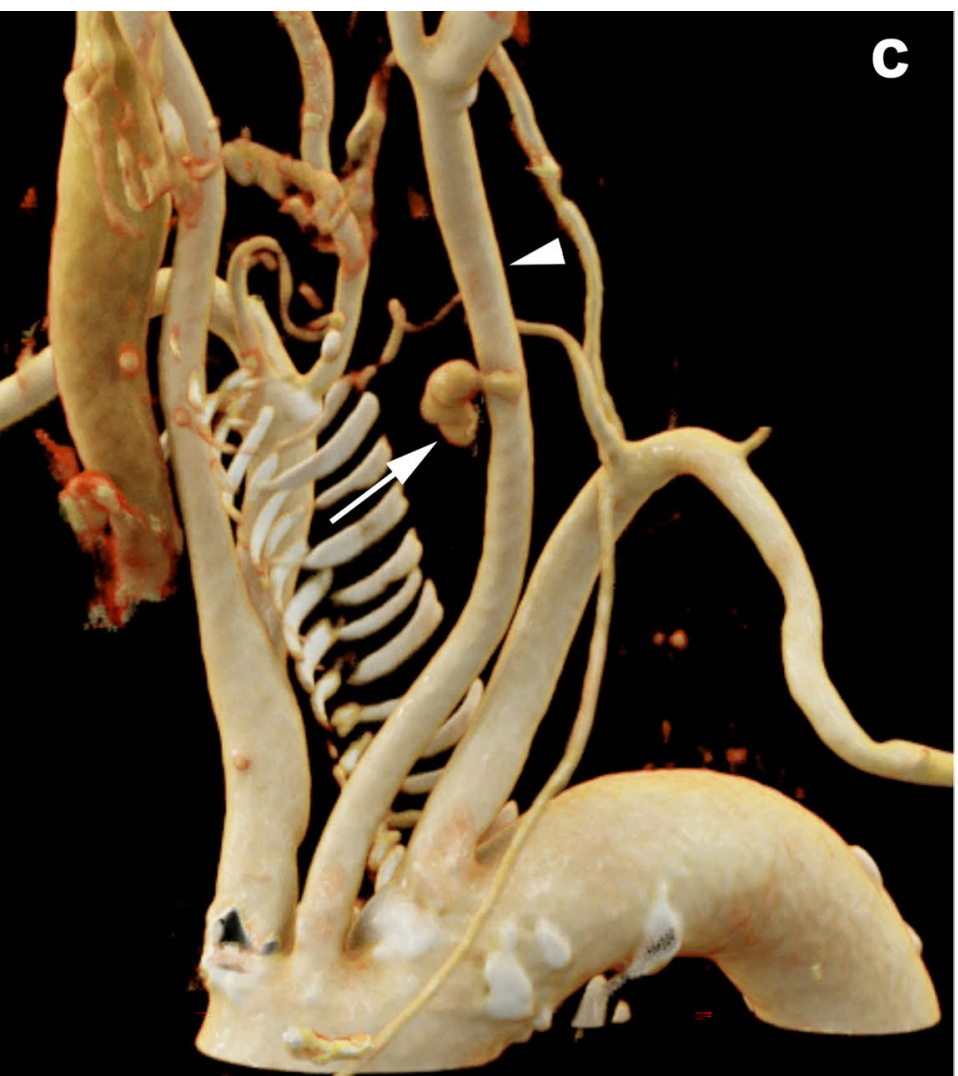

reconstruction of the CT angiography in LAO projection shows the pseudoaneurysm (arrow) anterior to the left common carotid artery (arrowhead) originating on the lateral aspect of the vessel wall 
Fig. 3 a, b Shape of the LOGIQ L8-18i finger probe. c Complete thrombosis of the pseudoaneurysm (arrow)
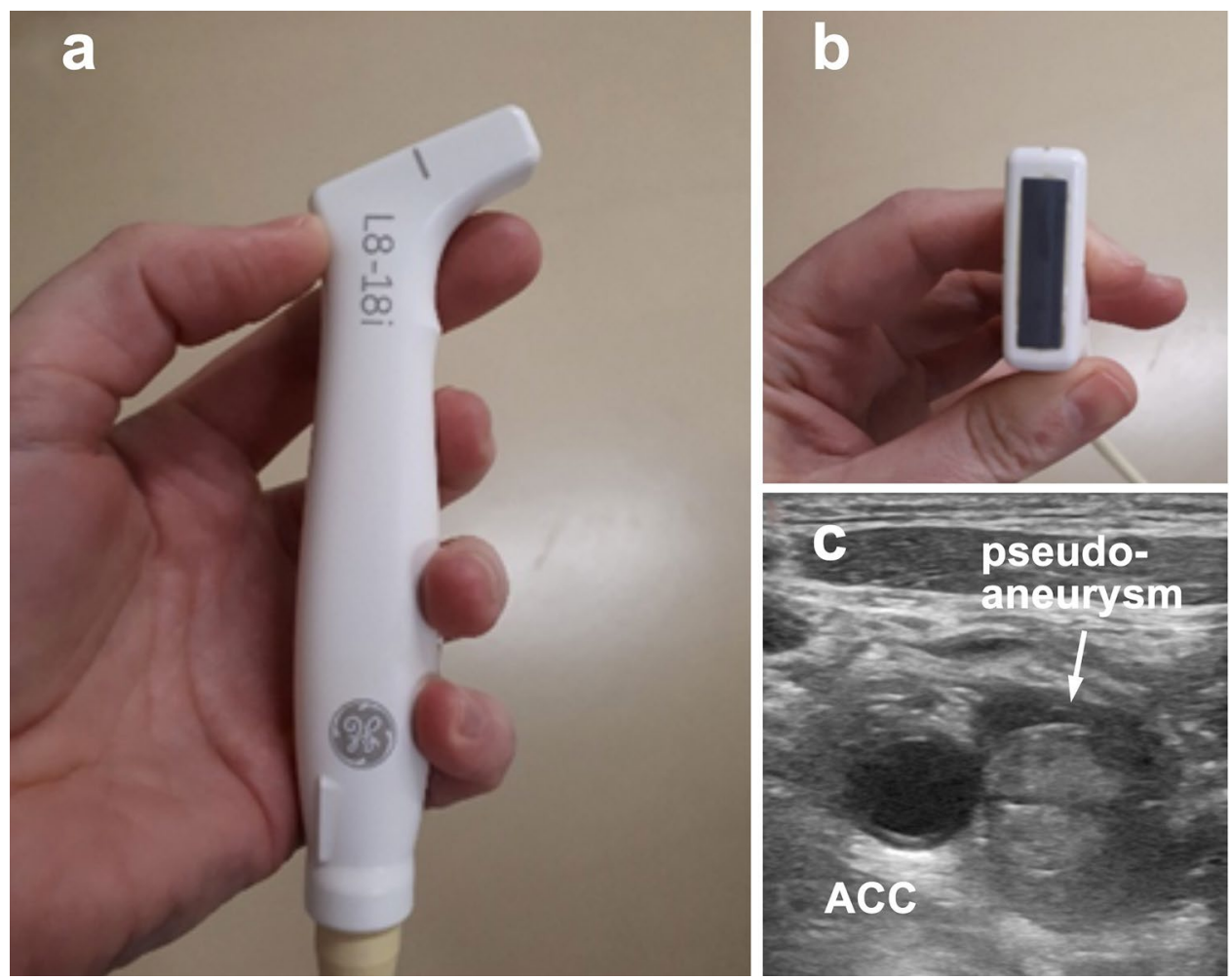

an ultrasound-guided puncture. The latter has shown to decrease vascular complications significantly [8]. If the vein is properly filled and not collapsing during inspiration, a controlled puncture of the anterior wall with subsequent catheter placement can be done safely. Especially if the vein lies in front of the artery in close proximity of each other, due to the thin venous wall and its high elasticity, pressure caused by the needle can lead to venous compression and an unintended arterial puncture may follow.

Funding Open Access funding enabled and organized by Projekt DEAL.

Open Access This article is licensed under a Creative Commons Attribution 4.0 International License, which permits use, sharing, adaptation, distribution and reproduction in any medium or format, as long as you give appropriate credit to the original author(s) and the source, provide a link to the Creative Commons licence, and indicate if changes were made. The images or other third party material in this article are included in the article's Creative Commons licence, unless indicated otherwise in a credit line to the material. If material is not included in the article's Creative Commons licence and your intended use is not permitted by statutory regulation or exceeds the permitted use, you will need to obtain permission directly from the copyright holder. To view a copy of this licence, visit http://creativecommons.org/licenses/by/4.0/.

\section{References}

1. Shah PM, Babu SC, Goyal A et al (2004) Arterial misplacement of large-caliber cannulas during jugular vein catheterization: case for surgical management. J Am Coll Surg 198(6):939-944

2. Schummer W, Schummer C, Voigt R et al (2003) Pseudoaneurysma - eine seltene komplikation nach vena jugularis interna punktion: Zwei fallberichte bei patienten nach lebertransplantation. Anasthesiol Intensivmed Notfallmed Schmerzther 38(8):542-546

3. Cuhaci B, Khoury P, Chvala R (2000) Transverse cervical artery pseudoaneurysm: a rare complication of internal jugular vein cannulation. Am J Nephrol 20(6):476-482

4. Naganur S, Santosh K, Kumar Sihag B (2020) Bailout subclavian artery stenting in a sick child with iatrogenic subclavian artery perforation: a case report. Egypt Heart J 72(1):19

5. Allende JN, Barreras Molinelli L (2018) Carotid pseudoaneurysm treated with a flow diverting stent. Eur J Vasc Endovasc Surg 56(5):740

6. Seward CJ, Dumont TM, Levy EI (2015) Endovascular therapy of extracranial carotid artery pseudoaneurysms: case series and literature review. J Neurointerv Surg 7:682-689

7. Tomai F, De Persio G, Petrolini A et al (2017) Acute pseudoaneurysm following carotid artery stenting. JACC 10(6):622-623

8. Lamperti M, Biasucci D, Disma N et al (2020) European Society of Anaesthesiology guidelines on peri-operative use ofultrasoundguided for vascular access (PERSEUS vascular access). Eur J Anaesthesiol 37:344-376 